\title{
VIRUS DISEASES OF THE CENTRAL NERVOUS SYSTEM :
}

\section{A REVIEW}

BY

\section{JAMES GEAR}

\section{South African Institute for Medical Research, Johannesburg}

\section{CLASSIFICATION}

The virus diseases of the central nervous system are of growing importance. Some are apparently increasing in incidence, others are newly recognized. Even in a country like Great Britain the more exotic types may be seen in these days when air travel has brought the remotest parts of the tropics within one or two days' travelling time of North-western Europe. They may be classified into two main groups (Rhodes, 1948) :

A. Primary neurotropic virus infections with recognized clinical syndromes, whose characteristic signs and symptoms result from involvement of the central nervous system.

B. Secondary infections due to ordinarily non-neurotropic viruses, in which involvement of the central nervous system occurs as a complication of a primary infection elsewhere in the body.

\section{A. Primary Neurotropic Virus infections}

The primary neurotropic virus infections may be differentiated on the serological reactions of the viruses, of which about forty antigenic types are known. A more useful classification is based on the anatomical incidence of the pathological lesions, with subdivisions, some based on the antigenic structure of the causative viruses, thus :

\section{Virus meningitis and meningo-encephalitis}

Lymphocytic choriomeningitis

Pseudolymphocytic choriomeningitis

Meningo-encephalitis due to the virus of mumps

Durand's disease

\section{Virus encephalitis}

1. ARTHROPOD-BORNE ENCEPHALITIDES

\section{i. Mosquito-borne}

(a) St. Louis encephalitis, Japanese B encephalitis, and West Nile infection

(b) Equine encephalomyelitis

Borna disease, Russian equine encephalitis

North American equine encephalitis (Eastern type), North American equine encephalitis (Western type), Venezuelan equine encephalitis
Semliki Forest virus and Bunyamwera virus infections

ii. Tick-borne (Ixodes sp.)

Louping ill

Russian spring summer encephalitis (Far Easterr? variety), and Russian spring summer encephalitis (Western variety)

iii. Vector unknown

Australian X disease

2. RABIES

Ordinary street virus spread by canines

'Oulou fato' virus spread by canines

Trinidad rabies spread by the vampire bati. (Desmodus rotundus murinus)

3. ENCEPHALITIS LETHARGICA (VoN ECONOMO'S EASE), JAPANESE A

Ascending myelitis due to $\mathrm{B}$ virus

4. ENCEPHALITIS POSSIBLY DUE TO VIRUSES AS UNIDENTIFIED

Virus poliomyelitis

Non-Lansing type

Lansing type

Miscellaneous viruses possibly causing paralysis simulating poliomyelitis

MM virus

Encephalomyocarditis virus

Mengo virus

\section{B. SECONDARY Virus Infections of THE} Central Nervous System

\section{Post-infective enCePhalitis}

Rarely follows dengue, herpes febrilis, herpes zoste? infective hepatitis, influenza, lymphogranulom inguinale, measles, mumps, rubella, sandfly feve? variola, and varicella.

2. Post-vaccinal encephalitis

Occasionally follows vaccination with living viruf vaccines against smallpox (vaccinia) and against yellow fever.

Vaccination against rabies is occasionally complicated by neurological accidents. This condition probably not the result of virus action, but it merits discussion in this section. 


\section{PRIMARY VIRUS INFECTIONS}

\section{Virus Meningitis and Meningo-encephalitis}

The best known of this group is lymphocytic choriomeningitis. The virus was first isolated by Armstrong and Lillie in 1934. The disease has a world-wide distribution. Infection is usually contracted from house mice, the normal carriers of the virus. Experimentally, the virus can be transmitted by arthropods, but the common route of infection is probably via the respiratory tract by the inhalation of infected particles, or by ingestion of food contaminated by infected rodent excreta.

Armstrong (1941) recognizes three forms of this disease, namely influenzal, meningitic, and meningoencephalitic types. He notes that most infections have no symptoms of meningeal involvement.

In typical cases the onset of the illness is sudden, with coryza and fever, followed by signs and symptoms of meningitis, headache, photophobia, vomiting, stiffness of neck and back, and positive Kernig's sign, often associated with squint, nystagmus, and papillodema. The febrile illness lasts three to six weeks and is rarely fatal. MacCallum and Findlay (1939) have described one case with paralysis of the lower limbs closely simulating poliomyelitis.

The cerebrospinal fluid, usually clear, is under increased pressure. The globulin content is increased, but sugar and chloride are normal. The cell count shows an increase in lymphocytes, usually to 100 to 250 per c.mm., but occasionally up to 1,500 per c.mm.

Pseudolymphocytic choriomeningitis is a similar condition caused by a similar, but antigenically distinct virus (MacCallum and others, 1939).

Discussing an outbreak of virus encephalomyelitis, Jennings (1947) suggests that other as yet unidentified viruses may also be concerned in causing lymphocytic meningitis. Tidy (1946) has noted the close similarity between benign lymphocytic meningitis and nervous forms of glandular fever.

Mumps virus may cause primary meningoencephalitis. Indeed such cases are not uncommon.

Durand's disease. (Findlay, 1942) is caused by a virus transmissible to guinea-pigs. Two laboratory infections in human beings have been described in North Africa. The illness in one of them was characterized by a biphasic temperature chart. During the second bout of fever the patient had intense headache, nausea, and vomiting, with occasional neuralgic pains in the back of the neck, thorax, and calf.

It is not known whether this virus naturally infects Man and, if so, whether the infection is widespread. Although this condition is here grouped with the virus meningitis, this is a tentative classification. It has been shown that there is no immunological relationship with the virus of choriomeningitis.

\section{Virus Encephalitis}

\section{ARTHROPOD-BORNE ENCEPhalitis}

Many of the virus infections of the central nervous system can be grouped together as arthropod-borne virus encephalitides since the viruses have been isolated from mosquitos, mites, and ticks, and there is convincing evidence that these invertebrate hosts are vectors and, occasionally, reservoirs of infection (Hammon, 1948). All are primarily infections of birds or animals. Man is infected only accidentally. Most of these infections have a limited geographical distribution but, as a group, they occur over wide areas of the world. They have a clearly defined seasonal incidence, depending on the seasonal prevalence of the arthropod vector. The group can be divided according to the common vector to Man into a mosquito-borne group and a tick-borne group.

Mosquito-borne Encephalitis.-The mosquitoborne infections can be subdivided on the antigenic relationship of the viruses into two further groups, namely St. Louis encephalitis group and the equine encephalomyelitis group.

St. Louis Encephalitis Group.-St. Louis encephalitis derives its name from an epidemic which occurred in St. Louis in 1933. Another outbreak occurred there in 1937. Since then outbreaks have occurred in other areas, and it is now clear, from serological studies, that this disease has a wide distribution in the United States. The virus infects domestic and wild birds. It is spread amongst them by mosquitos, such as Culex tarsalis, and the chicken mite Dermanyssus gallince. The latter acts as a true reservoir host, for infection may persist in them for several months and may be hereditarily transmitted to succeeding generations. The virus appears to be transmitted to Man by mosquitos, especially Culex tarsalis. As is to be expected, opportunities for infection of Man are greatest in rural and suburban areas.

An epidemiologically and clinically similar type of encephalitis, known as Japanese B encephalitis, has been recognized in Japan for many years. This also is a summer disease and large outbreaks involving thousands of cases have occurred. It is also spread by mosquitos, probably Culex tritceniorhynchus and Culex pipiens var. pallens. Serological studies have shown that there is antigenic overlap but not identity with the virus of St. Louis encephalitis. Sabin (1947) has recently noted the occurrence of cases of Japanese B encephalitis on Okinawa and the neighbouring islands. 
The West Nile virus was isolated from the blood of an African woman in the West Nile Province of Uganda, East Africa, who had fever but no definite signs of an encephalitis. She subsequently developed antibodies in her serum against the virus, so there is little doubt that her infection was actually due to the virus. The virus particles were approximately the same size as those of the virus of St. Louis encephalitis. By a series of cross-neutralization tests, Smithburn (1942) found that the West Nile virus was immunologically related to but distinct from the viruses of St. Louis and Japanese B encephalitis. Anti-serum against the West Nile virus does not neutralize either of these viruses. Vaccination with either of the three viruses causes enhanced resistance to the homologous strain only. The immunological relationship is shown by the fact that anti-sera against the St. Louis virus may cross-neutralize the West Nile virus and anti-sera against Japanese B virus have some power to crossneutralize both the West Nile and the St. Louis viruses.

It is noteworthy that these antigenically related viruses were isolated from widely separated regions of the world-St. Louis in North America, Japanese B in Japan, and the West Nile in Central Africa.

Equine Encephalomyelitis Group.-Equally widespread are the viruses constituting the equine encephalomyelitis group. These infections are also mosquito-borne. The virus of the Western type of North American equine encephalitis has also been isolated from chicken mites and from wild bird mites Liponyssus sylviarum, and possibly Dermanyssus americanus (Hammon, 1948). Of this group, European Borna disease of horses and Russian equine encephalitis are not known to infect Man. Antigenically these two viruses are distinct from each other and from the Eastern and Western types of North American equine encephalitis, which in turn are distinct from each other, though they share common antigens. Similar or related viruses have been described from Brazil (related to the Eastern type) and from the Argentine (related to the Western type). The Venezuelan type is distinct from both the Eastern and Western types.

The Semliki forest virus, and the Bunyamwera viruses were isolated from batches of mosquitos (Smithburn, 1948). In their physical and immunological properties, these viruses are related to the equine encephalomyelitis group. That they can cause infections of Man is apparent from the finding of neutralizing antibodies in sera from individuals in this region. However, the clinical characteristics of the illness they cause is not known. It is also not known whether they ever cause symptoms of encephalitis.

Human cases of encephalitis, due to the viruses of equine encephalomyelitis, have been described from many parts of North America. As is to be expected the disease most commonly affects those living ing rural areas where wild and domestic birds are thes source of infection. Man and horses are accidentak. hosts and the infection is transmitted to them by $\overrightarrow{2}$ mosquitos, especially Culex tarsalis.

Recently Hammon (1948) has suggested that this whole group of arthropod-borne encephalitides maye be inter-related and derived from a common stem virus. The clinical manifestations are similar $\frac{\bar{m}}{?}$ Following an incubation period of from four toळ twenty-one days, the onset of illness is acute, withes severe headache, dizziness, photophobia, nausea and. vomiting, and fever usually lasting one to two weeks? Some cases do not develop definite signs of $\vec{\omega}$ involvement of the central nervous system, but ine typical cases these symptoms at the onset of illness? are followed by encephalitic symptoms, neck rigidity, and mental confusion ; then nerve paralysis, $\vec{N}$ especially affecting the muscles of the eyes, causifg squints and diplopia, may develop. Aphasia māos occur. Often-the patient becomes stuporose 8 ro even comatose. Death occurs in approximater. one-third of the cases, nearly always within a fogt-T night of the onset. Of the non-fatal cases, two-문 thirds recover completely. The remainder are 1 efft with sequelæ, such as headaches, irritability, loss memory, and lethargy.

During the acute phase, the cerebrospinal fluid is clear but under increased pressure. There are from 50 to 250 cells per c.mm., including up to 50 per cent: neutrophils in the early stages. Later monocytes predominate.

In the cases of Japanese B encephalitis occurring amongst American military personnel on Okinawa, Sabin (1947) noted that the outstanding clinical $\overrightarrow{\overrightarrow{0}}$ features were " lethargic" consisting of drowsiness, $\frac{\exists}{7}$ lethargy, mental confusion and disorientation, and semicoma, or complete coma in the more severe? cases occurring in association with high fever, nuchal and spinal rigidity, leucocytosis, andō pleocytosis.

Tick-borne Encephalitis.-Louping ill, a wellồ known disease of lambs in Scotland and North England, is so called because of the peculiar gait of 0 affected lambs. It is transmitted by ticks, Ixodes $>$ ricinus, which in their larval stage become infected by sucking blood of an infected sheep, and are then infective in their nymphal and adult stages.

Laboratory infections of Man have occurred, $\stackrel{N}{\circ}$ four in the United States (Rivers and Schwentker, N 
1934), and two in Europe (Wiebel, 1937 ; Wesemeier, 1938). More recently in North England two naturally acquired infections in Man were described following bites of these ticks (Davison and Neubauer, 1948). The illness resembled that seen in three of the six laboratory infections in having a biphasic character, the meningo-encephalitic phase following the influenzal-like phase after several days of comparatively good health. A few days after the patient's exposure to tick bites, the illness began with malaise, headache, and fever, which continued for a week. There was then an afebrile interval of one to two weeks during which the patient recovered. Then the symptoms returned with increased intensity : severe headache with fever, vomiting, bradycardia, drowsiness, insomnia, confusion, tremors, and ataxia. The physical signs included neck stiffness, papillœdema, and cranial nerve palsies. The blood showed a leucocytosis of 10,000 to 12,000 per c.mm. with 70 to 80 per cent. neutrophils. The cerebrospinal fluid, which was clear or slightly bloodstained, contained from 50 to 500 cells, mostly lymphocytes, per c.mm. The protein content was slightly raised. The fever abated in a few days and the symptoms had largely cleared in a week, but it was a few weeks before one of the patients fully recovered. The other patient has permanent sequelæ. In convalescence the sera of these patients neutralized the virus of louping ill.

Russian spring summer encephalitis is also spread by a tick, Ixodes persulcatus, and probably also other species. Two varieties are recognized-a Far Eastern type, which gives rise to a severe, often fatal, disease in Man, and a milder Western type. The viruses are very closely related to that of louping ill. The Eastern type may be identical with it.

A disease known as Australian $\mathrm{X}$ disease, having resemblances to louping ill, occurred in Australia. It was first recognized in 1917 and 1918. These cases were characterized by an incubation period of from five to twelve days, a sudden onset of vomiting, headache, fever, drowsiness, twitchings, and muscular weakness and inco-ordination, and in children convulsions. The death rate was 70 per cent., death usually occurring within the first week. Those cases that recovered had fever for ten or twelve days, after which they rapidly improved and recovered without permanent sequelæ.

The cerebrospinal fluid showed pleocytosis. A virus was isolated from several cases. This virus was studied for its effect on experimental animals. In Man it was noted that there was a widespread destruction of Purkinje cells similar to that seen in monkeys infected with louping ill. As this virus has not been maintained, its relationship with louping ill and with the other viruses causing encephalomyelitis in Man has not been determined. It seems, however, to fall into this group of diseases.

The Diagnosis of Virus Encephalitides.-On clinical findings it is usually impossible to name the causative virus of a case of encephalitis. Fortunately reliable laboratory tests are available by which it may be identified. The first of these is the isolation of the virus from the blood or cerebrospinal fluid by the inoculation of experimental animals, usually the mouse, intracerebrally. Once isolated, the virus can be definitely identified in the laboratory by a detailed study of its antigenic and other characteristics. However, in many cases it is not possible during the life of the patient to isolate the virus, either from the blood or cerebrospinal fluid. In such cases the identification may be achieved by immunological methods. The most commonly used is the neutralization test. Known viruses are tested against the patient's serum. To be significant, it must be shown that, from being negative before or at the onset, or shortly afterwards, this test becomes positive later, usually after the first week of illness, or in the patient's convalescence. Complement fixation tests have also been evolved of value in the laboratory diagnosis of these virus infections. Antigens prepared by a benzene extraction method have given results superior to thóse given by antigens prepared by other methods (Espana and Hammon, 1947).

Prophylactic Vaccination.-In passing, it is of interest to note that formalinized vaccines prepared from infected mouse brains, or from chick embryos, have been found to be effective in conferring immunity against several of the virus encephalitides. These vaccines have been used to immunize large numbers of American soldiers in the Far East without serious untoward effects (Sabin, 1947).

\section{RABIES Group}

Rabies is an acute infection of the central nervous system caused by a virus, transmitted to Man by the bite of a rabid animal or by the contamination of abrasions or cuts by saliva of a rabid animal. There are two epidemiological types, namely the natural disease as it occurs in wild animals, and the urban type which is maintained in domestic dogs. In different parts of the world different animals are mainly responsible for the infection of Man. In Western Europe it is usually a dog. In Eastern and South Eastern Europe rabid wolves may also attack Man. In North Africa it is also the dog. In Central Africa the disease is often transmitted by jackals, occasionally by hyænas. In South Africa the important vector is the yellow mongoose, or meerkat, and occasionally other. 
small wild carnivora. In the United States coyotes as well as dogs may be concerned. In Trinidad the disease is transmitted by the vampire bat, Desmodus rotundus.

A number of different strains of rabies virus exist. Recently isolated strains from dogs are called street virus. Most street virus can be transformed, by passaging in series through rabbits inoculated intracerebrally, into virus fixe or fixed virus. Reinforce strains have an unusually high virulence for laboratory animals, possibly also for Man. The virus introduced into the wound invades the nerves and migrates to the brain, producing an acute fatal encephalitis. The incubation period is very variable-from ten days to over three years, commonly about three to twelve weeks. The first symptom is usually irritation at the site of the infecting bite. This is followed by a period of excitement characterized by constant activity, irritability, apprehension, and insomnia. There is increased reflex activity, typically manifesting itself in the classical hydrophobic symptom of painful spasmodic contractions of the throat when attempting to swallow. As the disease progresses, the paroxysms become more frequent and there may be gèneralized convulsive seizures. Later paralysis supervenes, and when the respiratory centres are involved, death occurs. The disease runs a rapid course and always ends fatally, usually within five days of the onset of symptoms. In some cases paralytic symptoms dominate the picture.

The Trinidad virus, spread by vampire bats, Desmodus rotundus, causes rabies of cattle (mal de caderas). In Man, it causes an ascending Landrylike type of paralysis.

Rabies, unless suspected, may be mistakenly diagnosed in the beginning as hysteria. The diagnosis is confirmed by the inoculation of laboratory animals, usually the rabbit or mouse, intracerebrally with suspensions prepared from the brains of suspected cases. These subinoculated animals develop the paralytic form and the characteristic Negri bodies can be demonstrated in sections of the brain.

Prophylactic vaccination with suspensions of rabbit spinal cord of patients bitten by a suspected rabid animal is occasionally followed by signs of serious damage to the central nervous system. These neuroparalytic accidents may take the form of a Landry-type of ascending paralysis with a death rate of about 30 per cent., or of dorsolumbar cord involvement with a death rate of about 5 per cent. More rarely cranial nerves are affected. The ætiology of these neuroparalytic accidents is discussed later in this paper. To avoid this complication, efforts are being made to develop a more highly refined vaccine in which the virus is in activated by ultra-violet light.

The urban type of rabies may be controlled b the measures in vogue for the last hundred years to prevent any dog from biting another for a periơ of the longest latency of the disease. These ard destroying all ownerless dogs, quarantining a owned dogs while rabies prevails, and for at leas six months after the last reported case, and quaran tining all imported dogs for six months. Vaccina-: tion of dogs, using killed virus vaccine, is recoms mended for use in places where protracted quarang tine cannot be enforced, or where the disease present in wild animals. If vectors among wiles animals are drastically reduced by hunting an $\bar{\phi}$ trapping, the disease cannot persist (Johnson, 1948)

The virus of pseudorabies or mad itch, primarily a disease of animals, has no relation to the virus of rabies.

\section{ENÇEPHALITIS LETHARGICA}

Sleepy sickness has occurred in previous centuries but the modern interest dates from the first worlit war, when a widespread outbreak occurred ia Western Europe. In England, the first cases were recorded in 1918. In 1924 over 5,000 cases vigre notified. The number of cases has progressivty fallen since then.

These cases were characterized by an incubatio period of three to twenty-one days, usually tén fourteen days. At the onset the patient complai of lethargy, insomnia, headache, giddiness, vomitîngsyeating, and fever. The illness then assumed on of several types. In the mesencephalic type there was somnolence, apathy and lethargy, and stuporo In the focal type variable affections of the crania neryes were seen, giving rise to various oculomoto dysfunctions, including ptosis, strabismus, diplopi宛 and bilateral ocular muscular paralyses, an occasionally to aphonia. The face was characte $\vec{b}$ istically impassive. In some countries epidemics of hiccough occurred co-incidentally with encepha litis, and these may have been another manifestation of this disease.

The illness lasted from four to ten weeks. About 50 per cent. of the patients died. Many of those that recovered have permanent sequelæ, including. mental disorders, Parkinsonism, and other manf festations of damage to the mesencephalon. I children a change to an amoral disposition somes times occurred.

The virus responsible for encephalitis lethargica remains unknown. As the first outbreaks cq5 incided with the pandemic of influenza, it has beeP suspected that there was an association between the two conditions, but there is little evidence of 
direct relationship. The virus of Herpes febrilis was isolated from the brains of several fatal cases, and from the nasopharynx of other cases. There is no doubt that this virus, on occasion, does give rise to encephalitis. However, it is frequently found in Man and it may have been an accidental invader of the central nervous system. Although it naturally remains under suspicion, its role in causing encephalitis lethargica is in doubt. Indeed, most authorities are of the opinion that it is not the cause, which still remains to be discovered.

Ascending Myelitis due to B Virus.-A virus having some affinities with the virus of Herpes febrilis was isolated from the brain of a man dying of an ascending myelitis following the bite of a laboratory monkey. This virus is known as B virus. Sabin and Wright (1934) noted that it closely resembles the virus of herpes but has properties which distinguish it from that virus; thu's it is pathogenic to rhesus monkeys, while the virus of herpes is not and, as Burnet and others (1939) concluded, the B virus has a more complex antigenic structure than herpes virus.

The laboratory worker concerned was bitten on the hand by an apparently normal monkey. Three days later he noticed an inflammatory reaction at the site of the bite with the formation of vesicles. Several days later he had cramps in the abdomen. He developed hyperæesthesia, and later flaccid paraplegia, and died of respiratory paralysis on the fourteenth day. This is the only case on record of an infection of Man due to this virus.

\section{Encephaltis Possibly due to Viruses as YET UNIDENTIFIED}

A number of outbreaks of encephalitis have been reported from different parts of the world, where for various reasons a detailed investigation of their ætiology was not possible. These include cases in East Africa (Charters, 1940), Southern Rhodesia (Berney and Gelfand, 1946), England (Greenfield, 1943), and several other countries. It seems probable that viruses were responsible for many of these outbreaks and it is clear that still further additions will have to be made to this group of the virus encephalitides.

\section{Virus Poliomyelitis (Inflammation of the Grey Matter of the Spinal Cord)}

Poliomyelitis is a disease of increasing importance. It was known in ancient Egypt, but has only assumed epidemic form in the last hundred years. These epidemics first occurred in the countries where the standard of living and of hygiene was highest. The first extensive epidemic occurred in Scandinavia in 1868. Later, in 1894, epidemics occurred in the
United States, later still in Australia and New Zealand. As other countries have attained comparable standards of living, they in turn have suffered from extensive outbreaks. During and since the recent war, epidemics have occurred in many regions of the world. Some experienced epidemics for the first time. England suffered the first widespread epidemic in the summer of 1947 . There is reason to believe that often these epidemics followed the introduction of more than usually virulent strains of virus, particularly from the Middle East.

From 'studies made during the war, it is now clear that poliomyelitis is a world-wide disease and that infection is more widespread in the backward and primitive countries of the Tropics and Subtropics than in the more highly developed lands of Western Europe and North America. However, the incidence of the paralytic form is much higher in the latter. The most likely explanation for this appears to be that in their insanitary surroundings, primitive peoples come into contact earlier and more regularly with endemic strains of the virus, and so acquire an immunity not shared to the same degree by more highly civilized peoples. The former thus are able to resist infection with epidemic invasive strains of the virus better than the latter. Differences in the staple diet may also play a part, for it has been shown that experimental animals on a thiamine-deficient diet are more resistant to infection than the normal animals.

Obviously it is of the greatest epidemiological importance that the number of strains of virus causing poliomyelitis should be accurately known. A start has been made in answering this question. Recent work by Morgan (1948) indicates that these may be divided into two main groups, namely :

(a) Non-Lansing type strains, which besides Man cause disease experimentally only in the primates. Of the non-Lansing strains so far tested, all have been of one immunological type. Further tests may reveal more types.

(b) Lansing type virus strains which, in addition to primates, are pathogenic to certain rodents including cotton rats and white mice. All the strains of human poliomyelitis that have proved pathogenic to rodents have been found to be immunologically similar and of the Lansing type.

At the recent Conference in New York on poliomyelitis, held under the auspices of the National Foundation for Infantile Paralysis, it was decided that the name poliomyelitis should be restricted to these two types of virus. It was decided that the disease of mice caused by Theiler's virus, often called mouse-poliomyelitis, should be known by the name Theiler (1941) originally gave 
it, namely spontaneous mouse encephalomyelitis. Although he realized that the virus and the disease it caused had many characteristics in common with the virus and disease of human poliomyelitis, he purposely did not call it mouse poliomyelitis. Unfortunately others did not follow his lead, and considerable confusion has resulted from the use of the term mouse poliomyelitis.

Confusion regarding the MM virus, usually called the MM strain of poliomyelitis, also exists. There is doubt as to its origin. In view of this it was decided that the MM virus, and similar viruses, should not be included in the poliomyelitis group. Recent work has added considerably to the interest of the MM virus. It has been shown to be immunologically similar to the virus of encephalomyocarditis, which was isolated from a dead chimpanzee in Florida (Warren, 1948). These viruses both cause a fatal encephalitis when inoculated intracerebrally in mice. Another virus, apparently of this group, was isolated by Dick and others (1948) from a paralysed monkey in the compound of the Yellow Fever Research Station at Entebbe. Similar viruses were then isolated from mosquitos and a mongoose caught in the area. The fact that Mengo virus was isolated from mosquitos on one occasion suggests, but does not prove, that these insects may have a part in its transmission. Then Dick himself became ill, with intense headache and fever, during which he developed nerve deafness and weakness of the trapezius. A similar virus was isolated from his blood. Neutralizing antibodies to this virus were shown to be present in his serum during convalescence. This virus has been named Mengo virus, after the province in Uganda where it was isolattod. In more recent work Dick has shown that Mengo virus is closely related to the virus of encephalomyocarditis. The viruses thus discovered have been isolated from widely scattered points. It thus appears that this group of viruses may have a wide distribution in the world. How often they cause disease in Man is not yet known and whether the illness often simulates true poliomyelitis has not yet been determined. Dalldorf and Sickles (1948) recently isolated a filterable agent from the fæces of children during the acute phase of an illness resembling poliomyelitis. This agent produces paralysis and muscle lesions in suckling mice and hamsters but not in rhesus monkeys. Further reports will be awaited with interest.

The Spread of Poliomyelitis.-Although it is not yet certain how poliomyelitis is most commonly spread, a considerable amount of evidence has been collected in regard to the problem. In patients, the virus is found in the throat four or five days prior to the onset of symptoms and for three or four days afterwards. Apart from this limited period the virus has only rarely been detected in the throat: though in one investigation it was detected in two patients eleven days after the onset (Pearson and Brown, 1947). It is present in the fæces of mosto patients regularly for three weeks and in a smals proportion for as long as eight weeks and, occasion $\frac{\overline{0}}{\mathrm{~N}}$. ally, for twelve weeks (Horstmann and others $\vec{z}$ 1944). Observations by Gordon and others (1948) and by Aycock and Kessell (1943) have indicated that the infectious period of cases extends from fouro days before to five days after the onset of symptoms $\underline{\underline{O}}$ This period corresponds to the time when the virusc. is most commonly present in the throat. It suggests $\mathbb{D}$ then, that spread takes place from the throat virus If fæcal virus were responsible for spread during contact, the period of infectiousness of a case would begin earlier and last longer than has been found to $\vec{\omega}$ be the case.

However, the acceptance of the respiratori droplet transmission hypothesis leaves unexplained the remarkable seasonal incidence of poliomyelitis $\vec{N}$ Although winter epidemics have been described? epidemics in temperate climates occur almgsf always in the summer and autumn. This is tine time of the year when known alimentary infective diseases like typhoid and dysentery are commonest and also when insects and other arthropods ore most prevalent. This naturally has raised question as to whether poliomyelitis may not bege alimentary infective disease or an arthropod-boriedisease, especially as abundant virus occurs in fæces. The virus has been isolated a number of times from batches of flies, since Paul and others first demonstrated its presence in flies in 1941. The suspicion that flies may play a major role in the spread of poliomyelitis has been further strengthene by the recent observations of Melnick and Pennep (1947) that, after feeding on infected human stools $\vec{\sigma}$ the blowfly Phormia regina continued to excrete virus for two or three weeks. Under similap conditions Theiler's virus or inert carmine were. detectable for three to five days only. These findings suggest that there may be a biologicas relationship between flies and the virus, though it still remains to be proved that the virus actually. multiplies in the fly. However, there are so mans clear instances of spread from human to human that there is general agreement that this is a commoro method of spread. It is not clear whether infection takes place by respiratory droplets or by hand-ton mouth contamination. There is also no doub that of those infected only a minority develop symptoms, and still fewer develop paralysis. It has long been suspected that fatigue and violentw 
exercise predispose an infected individual to a paralytic attack. Ritchie Russell (1947) has confirmed this suspicion by his enquiry into the history of severely paralysed cases. This revealed that nearly all these cases had indulged in severe or prolonged exercise within a probably significant period before they became ill, or during the preparalytic stage. In contrast those who escaped with light paralysis or had non-paralytic attacks had been relatively quiet in the corresponding period.

There is also little doubt that operations on the throat shortly after or shortly before infection predispose an individual to a bulbar form of the disease. Extraction of teeth, and also carious teeth, may similarly provide a portal of entry for the virus, though there is little direct evidence to incriminate them.

Pathological studies of fatal human cases have revealed that the virus does not gain entrance to the central nervous system via the olfactory nerves and bulb. This is the route often taken in monkeys experimentally infected by intranasal instillation. The work of Faber and others (1948) suggests that the nerves of the throat may be especially implicated in human infections.

Prevention of Spread.-Experience has shown that all measures usually enforced-the isolation of cases, the closing of swimming baths and schools, and places of entertainment-have little effect in preventing the spread of poliomyelitis. To be of value, isolation would have to include all the members of each affected household, and the period would have to be extended from three to eight weeks. Such stringent isolation is usually not possible, and even when practicable is often unavailing. Indeed it could hardly be otherwise in a disease in which only a small proportion of those capable of spreading infection have symptoms of illness.

The only solutions to this problem appear to be the development of a prophylactic vaccine, or the discovery of a chemical or other agent which will either inactivate the virus or prevent its access to the susceptible nerve cells. Needless to say, intensive efforts are being made to develop a safe effective vaccine and also to discover a drug which will act prophylactically to prevent infection. It is to be hoped that these endeavours will soon be successful.

Diagnosis of Poliomyelitis.-There is no routine laboratory test yet available for the diagnosis of poliomyelitis. Attempts have been made, and are being continued, to develop complement fixation and flocculation tests. There is a great need for such diagnostic tests, and it is to be hoped one will soon be developed. At present the only laboratory method of determining whether an illness is or is not poliomyelitis is by demonstrating the yirus by the inoculation of monkeys. The materials usually tested are throat washings taken from the patient within three days of onset, or more certainly, fæces collected within three weeks of onset or, in fatal cases, suspensions prepared from the spinal cord and brain stem. Fortunately, paralytic poliomyelitis is readily diagnosed on clinical grounds though a number of conditions may cause confusion. One of the most difficult to distinguish from poliomyelitis is polyneuronitis, or the Guillain Barré syndrome. This syndrome is generally assumed to be due to a virus, though its presumptive virus has not yet been isolated. Clinically, after an interval of three to six weeks following an upper respiratory infection, the patient develops weakness and paralysis of various groups of muscles, usually symmetrical in distribution. If not fatal because of involvement of the respiratory muscles as it sometimes is, recovery from the paralysis is usually complete. It is, therefore, important in giving a prognosis to be able to differentiate this condition from poliomyelitis. This can be done by the examination of the cerebrospinal fluid. In the Guillain Barré syndrome there is an increased protein content, but there is no increase in the number of cells. In poliomyelitis the protein and the cells are both increased. In the early stages neutrophils form a large proportion of the cells, later lymphocytes predominate. In the recovery stage, however, the cell count may return to normal, whereas the protein content remains elevated for a longer time.

Two cases of infectious mononucleosis associated with ascending paralysis indistinguishable from that of the Guillain Barré syndrome have been described (Ricker and others, 1947). Both ended fatally. Post diphthertic neuritis may closely resemble the Guillain Barré syndrome. Differentiation depends on the demonstration of diphtheria bacilli and on the relatively slight elevation of the spinal fluid protein. Similarly in four cases of polyneuritis associated with the ingestion of large amounts of sulphonamides over long periods, there was no elevation of the total protein level in the spinal fluid (Hand and Rudoy, 1948).

It is also of great importance from the point of view of prognosis to be able to distinguish poliomyelitis from encephalitis lethargica. The ultimate prognosis in encephalitis lethargica may be serious even though the acute attack has been mild and the patient apparently fully recovered, for about half the surviving cases later develop sequelæ, most 
frequently Parkinsonism. On the other hand, in poliomyelitis the maximum involvement usually occurs within forty-eight hours, and nearly always within one week of the first recognition of paralysis. Thereafter any change will be for the better. This differentiation in routine practice has to be made on clinical findings and is sometimes very difficult.

Comparing the pathological pictures of encephalitis lethargica, Japanese B encephalitis, and poliomyelitis, Scheinker (1948) noted a similarity of the essential pathological features, namely a primary involvement of the nerve cells of the grey matter, predominantly focal in character and accompanied by focal proliferation of microglia cells with the formation of glial nodules. The differentiation of these diseases is based chiefly on the distribution of the pathological lesions. In cases of Japanese B encephalitis, the cerebral cortex, the thalamus, and the substantia nigra are most severely affected. The lesions of the cerebellum, the medulla, and the spinal cord, are discrete and inconstant.

In human poliomyelitis the brunt of the morbid process is borne by the nerve cells of the grey matter of the spinal cord, and of some of the cranial nerve nuclei of the medulla and the midbrain. The lesions of the pons, the cerebellum, and the basal ganglion are discrete and not constant. The cerebral cortex is often spared.

In encephalitis lethargica the lesions are. found particularly in the basal ganglia and the substantia nigra. Discrete focal lesions may be seen in the midbrain and pons ; they are as a rule absent from the cerebral cortex, the cerebellum, and the spinal cord.

\section{SECONDARY VIRUS ENCEPHALOMYELITIS}

Several familiar, usually non-neurotropic, virus diseases of Man may be complicated by involvement of the central nervous system. This complication is rare but appears to be increasing in incidence. It has been described as following dengue, herpes febrilis, herpes zoster, infective hepatitis, influenza, lymphogranuloma inguinale, measles, mumps, rubella, sandfly fever, variola, and varicella. Although the primary diseases are quite different, the signs and symptoms of the nervous involvement are essientially similar, and appear one to two weeks after the onset of the primary illness. There is a recrudescence of fever with a sudden onset of meningitic and cerebral signs and symptoms, including convulsions in small children, headache, neck rigidity, vomiting, a dulled intellect, drowsiness, stupor increasing to coma, and paralysis usually affecting the cranial nerves and often resulting in squints.
The blood shows a polymorphonuclear leucocy- $\bar{z}$ tosis. The cell count of the cerebrospinal fluid is increased up to 50 to 500 cells, mostly lymphocytes, per c.mm. The protein content is raised.

The severity of the post-infective encephalitis bears no relation to the severity of the precedinger exanthem. The prognosis appears to vary some-s what with the different primary diseases. In mumps, which occasionally present as encephalitis,

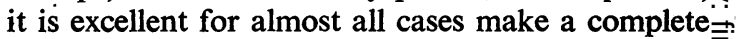
recovery. In measles, in which there appears to be an increasing incidence of encephalitis, for in? Chicago in $1937-8$ it was 1 in 15,000 cases흘 whereas in 1946 it occurred as frequently as 1 per $\frac{\bar{\Phi}}{\bar{\rho}}$ 642 cases (Hoyne and Slotkowski, 1947), the mortality® rate is from 10 to 15 per cent. In chickenpox, in which encephalitis often assumes a cerebellar ataxic $\vec{\sim}$ form, the prognosis varies but is often grave? (Forman, 1946).

In clinical symptoms and pathology post-infective encephalitis has many resemblances to post-vaccinial $\overline{3}$ encephalitis. Although isolated cases had occurred? and been described before then, this condition first $\vec{\sim}$ attracted general attention in 1922-3, when it.assumed serious proportions. It is now recognized as one of the most serious risks to be taken vaccinating against smallpox. 'The incidence varionsin different parts of the world. It assumed particy. Tा larly alarming proportions in Holland, where it was the custom to vaccinate children just before goipg to school. The condition is rarely seen in infants under two years old. When it occurs it neas $\vec{\varphi}$ always follows primary vaccination and is rarefy seen following second or later vaccination.

The first symptoms develop ten to thirteen days after vaccination; most cases begin on the twelfth day. The child suddenly becomes ill, with fever, $\bar{Q}$ headache, vomiting; occasionally convulsions, $\frac{\varrho}{\mathbb{D}}$ squints, and drowsiness progressing to coma, and $\stackrel{\varrho}{\rightarrow}$ in from 30 to 50 per cent. of cases to death. The $\overrightarrow{\underline{0}}$ blood 'shows a neutrophil leucocytosis and the 3 cerebrospinal fluid an increase in cells up to 100 to 200 per c.mm., mostly lymphocytes and mononuclear cells. At necropsy the meniges are congested, and microscopically there is a mild inflam-? matory reaction with infiltration of lymphocytes, $\frac{-}{3}$ plasma cells, and endotheloid cells. The brain substance shows congestion and areas of softening. $\overline{\text {. }}$ Microscopically the outstanding feature is wide perivascular demyelinization, especially round the $\mathrm{O}$ veins. There is slight perivascular-infiltration of inflammatory cells and also a diffuse cellular infiltration of the brain substance. Hyaline thrombi may be seen in the blood vessels. The nerve cells o are usually well preserved. In general, the white $\tilde{O}$ matter is more affected than the grey. 
Occasionally encephalitis has followed vaccination against yellow fever with a substrain of the avirulent 17D strain, or with the French neurotropic strain (Fox and others, 1942). These cases nearly all recovered.

As post-infective encephalitis and post-vaccinial encephalitis have similar pathological lesions, it is probable they have a similar xtiology. Several theories have been advanced to explain their development. It has been suggested that it is an inflammation due to the virus itself, or that it is an activation of an encephalogenic virus already present. The most likely explanation is that it is what might be termed an auto-allergic reaction to virus combined with some constituent of the nervous tissue.

The neuroparalytic accidents following therapeutic rabies vaccination may be discussed with advantage at this stage. In a small but apparently increasing proportion of cases treated by multiple injections of inactivated virus in central nervous system tissue, a serious nervous involvement occurs. This usually develops late in the course of injections, most commonly between the twelfth and fifteenth day of treatment. Clinically the condition commonly assumes a dorso-lumber type. The patient has fever and the lower limbs become paralysed. There is often paralysis of the sphincters as well. The death rate of this form is about 5 per cent. In some cases it assumes a Landry type and, following paralysis of the lower limbs, the upper limbs are affected, later the face. In this form about onethird of the cases die.

In the neuritic type, the patients have fever during which they develop paralysis of one or more of the cranial nerves.

In those cases that recover, recovery is usually complete. It has been stated that demyelinization is not an outstanding feature of the post-mortem findings, although most authorities consider that this condition is closely related to post-vaccinial encephalitis.

Experiments carried out by Kabat and others (1947) and Morgan (1947) support the hypothesis that post-infective and post-vaccinial encephalomyelitis may be regarded as auto-allergic or autoantigen-antibody reactions to some component of the central nervous system tissue made autoantigenic by the presence of virus. The neuroparalytic accidents following anti-rabies vaccination may similarly be regarded as reactions due to the development of antibodies to this component, following the injections of nervous tissue.

In these experiments a picture resembling acute disseminated encephalomyelitis in the human being was produced regularly and rapidly in rhesus monkeys by injections of emulsions of homologous monkey brain administered with an adjuvant, paraffin oil, in which heat-killed dried tubercle bacilli were suspended.

Morgan noted that positive reactions occurred only in response to central nervous system tissue containing white matter. An analysis of the results suggests that the antigen concerned is the myelin of the white matter of central nervous system.

It is interesting to speculate whether a number of other obscure conditions of the central nervous system like disseminated sclerosis, many drug encephalopathies, amyotrophic lateral sclerosis, Schilder's disease, and others, may not be manifestations of similar auto-antigen-antibody or autoallergic reactions. This, however, is a large subject and merits full discussion on its own.

\section{REFERENCES}

Armstrong, C. (1941). Bull. N.Y. Acad. Med., 17, 295. and Lillie, R. D. (1934). Publ. Hlth. Rep. Wash., 49, 1019.

Aycock, W. L., and Kessell, J. F. (1943). Amer. J. med. Sci., 205, 454.

Berney, B.P., and Gelfand, M. (1946). . E. Afr. med. J., 23, 174.

Burnet, F. M., Lush, D., and Jackson, A. V. (1939). Aust. J. exp. Biol. med. Sci., 17, 35.

Charters, A. D. (1940). E. Afr. med. J., 16, 459.

Dolldorf, G., and Sickles, G. M. (1948). Science, 108, 61.

Davison, G., and Neubauer, C. (1948). Lancet, $2,453$.

Dick, G. W. A., Best, A. M., Haddow, A. J., and Smithburn, K. C. (1948). I Ibid., $2,286$.

Espana, C., and Hammon, W. McD. (1947). Proc. Soc. exp. Biol. N.Y.; 66, 101 .

Faber, H. K., Silverberg, R., Dong, L., Luz, L. (1948). "Entry and Excretion of Poliomyelitis." Proc. First Internat. Poliomyelitis Conference.

Findlay, G. M. (1942). Trans. R. Soc. trop. Med. Hyg., $35,303$.

Forman, F. (1946). Clin. Proc., 5, 299.

Fox, J. P., Lennette, E. H., Manso, C., and Aguiar, J. R. S. (1942). Amer. J. Hyg., 36, 117.

Gordon, F. B., Schabel, F. M., Casey, A. E., and Fishbein, W. I. (1948). J. infect. Dis., 82, 294.

Greenfield, J. G. (1943). Proc. R. Soc. Med., 36, 321.

Hammon, W. McD. (1948). Amer. J..trop. Med., 28, 515.

Hand, M., and Rudoy, M. (1948). Ann. int. Med., 29, 91.

Horstmann, D. M., Ward, R., and Melnick, J. L. (1944). J. Amer. med. Ass., 126, 1061.

Hoyne, A. L., and Slotkowski, E. L. (1947). Amer. J. Dis., Child., 73, 554.

Jennings, G. H. (1947). Lancet, 1, 471.

Johnson, H. N. (1948). " Methods of Rabies Control." Proc. Fourth Internat. Congr. trop. Med. Mal. (In the press.)

Kabat, E. A., Wolf, A., and Bezer, A. E. (1947). J. exp. Med., 85, 117.

MacCallum, F. O., and Findlay, G. M. (1939). Lancet, 1, 1370.

1, Findlay, G. M., and Scott, T. McN. (1939). Brit. J. exp. Path!, 20, 260. 
Melnick, J. L., and Penner, L. R. (1947). Proc. Soc. exp. Biol. N.Y., 65, 342.

Morgan, I. M. (1947). J. exp. Med., 85, 131.

(1948). "Mechanisms of Immunity in Poliomyelitis." Proc. First Internat. Poliomyelitis Conference.

Paul, J. R., Trask, J. B., Bishop, M. B., Melnick, J. L., and Casey, A. E. (1941). Science, 94, 395.

Pearson, H. E., and Brown, G. C. (1947). Proc. Soc. exp. Biol. N: Y., 66, 503.

Rhodes, A. J. (1948). Canad. med. Ass. J., 59, 32.

Ricker, W., Blumberg, A., Peters, C. H., and Widerman, A. (1947). Blood, 2, 217.

Rivers, T. M., and Schwentker, F. F. (1934). J. exp. Med., 59, 669.
Russell, W. Ritchie (1947). Brit. med. J., 2, 1023.

Sabin, A. B. (1947). J. Amer. med. Ass., 133, 281. 115 .

Scheinker, I. M. (1948). Arch. Pathol., 45, 289.

Smithburn, K. C. (1942).- J. Immunol., 44, 25.

-(1948). "Neurotropic Viruses in Central Africa" Proc. Fourth Internat. Congr. trop. Med. Mal. (In the Press.)

Theiler, M. (1941). Medicine, $20,443$.

Tidy, Sir Henry (1946). Lancet, $2,819$.

Warren, J. (1948). Personal communication.

Wesemeier, K. (1938). Dtsch. Arch. Klin. Med., 18 $\overrightarrow{\mathrm{E}}$ 451.

Wiebel, H. (1937). Klin. Wschr., 16, 632. 